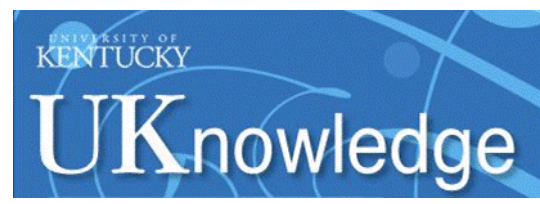

University of Kentucky

UKnowledge

\title{
Fluorinated N,N'-Diarylureas as Novel Therapeutic Agents Against Cancer Stem Cells
}

\author{
Dasha E. Kenlan \\ University of Kentucky \\ Piotr G. Rychahou \\ University of Kentucky, piotr.rychahou@uky.edu \\ Vitaliy M. Sviripa \\ University of Kentucky, vitaliy.sviripa@uky.edu \\ Heidi L. Weiss \\ University of Kentucky, heidi.weiss@uky.edu \\ Chunming Liu \\ University of Kentucky, chunming.liu@uky.edu
}

See next page for additional authors

Follow this and additional works at: https://uknowledge.uky.edu/markey_facpub

Part of the Cancer Biology Commons, and the Oncology Commons

Right click to open a feedback form in a new tab to let us know how this document benefits you.

\section{Repository Citation}

Kenlan, Dasha E.; Rychahou, Piotr G.; Sviripa, Vitaliy M.; Weiss, Heidi L.; Liu, Chunming; Watt, David S.; and Evers, B. Mark, "Fluorinated N,N'-Diarylureas as Novel Therapeutic Agents Against Cancer Stem Cells" (2017). Markey Cancer Center Faculty Publications. 131.

https://uknowledge.uky.edu/markey_facpub/131

This Article is brought to you for free and open access by the Markey Cancer Center at UKnowledge. It has been accepted for inclusion in Markey Cancer Center Faculty Publications by an authorized administrator of UKnowledge. For more information, please contact UKnowledge@lsv.uky.edu. 


\title{
Fluorinated N,N'-Diarylureas as Novel Therapeutic Agents Against Cancer Stem Cells
}

\author{
Digital Object Identifier (DOI) \\ https://doi.org/10.1158/1535-7163.MCT-15-0634 \\ Notes/Citation Information \\ Published in Molecular Cancer Therapeutics, v. 16, issue 5, p. 831-837. \\ (C) 2017 American Association for Cancer Research
}

The copyright holder has granted the permission for posting the article here.

The document available for download is the authors' post-peer-review final draft of the article.

\section{Authors}

Dasha E. Kenlan, Piotr G. Rychahou, Vitaliy M. Sviripa, Heidi L. Weiss, Chunming Liu, David S. Watt, and B. Mark Evers 


\section{Fluorinated N,N'-Diarylureas As Novel Therapeutic Agents Against Cancer Stem Cells}

Dasha E. Kenlan ${ }^{1}$, Piotr Rychahou ${ }^{1,2}$, Vitaliy M. Sviripa ${ }^{3}$, Heidi L.Weiss ${ }^{1}$, Chunming Liu ${ }^{3}$, David S. Watt ${ }^{3}$, and B. Mark Evers ${ }^{1,2}$

${ }^{1}$ Lucille Parker Markey Cancer Center, ${ }^{2}$ Department of Surgery, ${ }^{3}$ Department of Molecular and Cellular Biochemistry, University of Kentucky, Lexington, KY 40536, United States

Running Title: FNDs in colorectal cancer treatment

Keywords: Colorectal cancer; stem cells; AMPK; N,N'-diarylureas; metastasis; chemotherapeutic

\section{Abbreviation List}

AMPK - AMP activated protein kinase

CRC - Colorectal cancer

DMSO - dimethyl sulfoxide

FND - fluorinated N,N'-diarylureas

PDX - patient-derived xenograph

ROS - reactive oxygen species

*Corresponding Author: B. Mark Evers, M.D.

Markey Cancer Center

University of Kentucky

800 Rose Street, CC140 
Lexington, KY 40536

Phone: 859-323-6556, Fax: 859-323-2074

E-mail: mark.evers@uky.edu

Conflict of Interest: The authors declare no conflicts of interest.

Classification: Biological Sciences; Medical Sciences

Word count (excluding references): $\underline{3984}$

Number of figures and tables: 7 (5 figures, 2 tables)

Financial support: NCI P30 CA177558 (B.M. Evers), NCATS UL1TR000117 (B.M. Evers), R01 DK048498 (B.M. Evers), Markey Cancer Foundation (B.M. Evers), NIH R21 CA139359 (C. Liu and D.S. Watt), NIH R21 CA172379 (C. Liu and D.S. Watt), Office of the Dean of the College of Medicine (D.S. Watt), NIH P20 RR020171 (D.S. Watt). 


\begin{abstract}
Colorectal cancer (CRC) is the second-leading cause of cancer-related mortality in the United States. Over $50 \%$ of patients with CRC will develop local recurrence or distant organ metastasis. Cancer stem cells play a major role in the survival and metastasis of cancer cells. In this study, we examined the effects of novel AMP-activated protein kinase (AMPK) activating compounds on CRC metastatic and stem cell lines as potential candidates for chemotherapy. We found that activation of AMPK by all fluorinated N,N-diarylureas (FND) compounds at micromolar levels significantly inhibited the cell cycle progression and subsequent cellular proliferation.

Additionally, we demonstrated that select FNDs significantly increased apoptosis in CRC metastatic and cancer stem cells. Therefore, FNDs hold considerable promise in the treatment of metastatic CRC, through elimination of both regular cancer cells and cancer stem cells.
\end{abstract}




\section{INTRODUCTION}

Colorectal cancer (CRC) is the second leading cause of cancer deaths in the United States (1). This high mortality rate is largely attributed to tumor metastasis and recurrence (2). At initial presentation, more than half of all patients display metastatic disease in regional lymph nodes or systemic organs (e.g., liver). The five-year survival rate for patients with metastatic CRC is approximately $13 \%$, as compared to $90 \%$ for non-metastatic disease (1). A growing body of evidence suggests that cancer stem cells play a role in the resistance and spread of cancer cells (2-4). Cancer stem cells are a subpopulation of tumor cells that are capable of self-renewal and display resistance to DNA damage-induced cell death, a ruinous property that allows metastatic tumors to survive initial treatments and re-populate. Developing new anti-neoplastic agents that selectively target cancer stem cells represents a potentially valuable treatment to improve CRC outcomes (2-4).

Cancer stem cells possess demanding metabolic requirements and survival mechanisms that are potential targets for treatment (5). One such critical pathway involves AMP-activated protein kinase (AMPK), which coordinates growth, autophagy, and metabolism (6). AMPK acts as a metabolic sensor for the ratio of AMP to ATP in cells and has several downstream transcriptional targets (6). Among the anti-neoplastic effects of AMPK activation are cell cycle

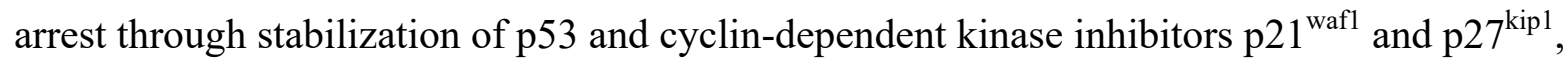
inhibition of macromolecular synthesis, inhibition of mTORC1, and inhibition of the Warburg effect $(7,8)$. In support of the particular importance of AMPK in cancer cells and cancer stem cells, the widely studied AMPK activator, metformin, reduces cancer incidence in diabetic populations for many different cancers, including CRC (9). Furthermore, in vitro and in vivo studies with metformin specifically show cytotoxicity toward cancer stem cells $(10,11)$. 
We identified the anti-neoplastic effects of fluorinated N,N'-diarylureas (FNDs) in a high-throughput screening program (12) and found that several potent FNDs inhibited growth of CRC cell lines through inhibition of the mTOR pathway (12). Overexpression of mTORC1 and mTORC2 components, Raptor and Rictor, is important to tumorigenesis (13), and the activation of AMPK regulates cell growth by suppressing mTORC1 through direct phosphorylation of the tumor suppressor, TSC2, and Raptor (6). Through this mechanism, we anticipated that AMPK activation would directly inhibit CRC cell proliferation.

In this study, we investigated the ability of eight FNDs to inhibit growth and induce apoptosis in CRC metastatic cell lines and stem cells. Activation of AMPK by all FND compounds successfully inhibited cell cycle progression and subsequent cellular proliferation. These results demonstrate that FNDs exhibit considerable promise in the treatment of metastatic CRC, predominantly through the inhibition of CRC stem cells.

\section{MATERIALS AND METHODS}

FNDs. FNDs were synthesized as previously described (12). Table 1 shows the FNDs used in this study. Stock solutions $(10 \mathrm{mM})$ in dimethyl sulfoxide (DMSO) were stored at $-20^{\circ} \mathrm{C}$.

Cell lines and culture maintenance. Human cell line HT29 was purchased from American Type Culture Collection. KM20 was provided by Dr. Isaiah J. Fidler (M.D. Anderson Cancer Center, Houston, TX); STR validation analysis (Bio-Synthesis, Lewisville, TX) yielded a full DNA profile and no contamination by another human cell line was detected; there were no matches after searching ATCC, JCRB or DSMZ databases. HCT116 pik3ca wild-type and mutant cell lines were a gift from Dr. J. Wang (14). Human CRC stem cell line 1 (\#36112-39; lot 
$\# 12121800-05)$ and stem cell line 2 (\#36112-39; lot \#1313161-12) were purchased from

Celprogen (Torrance, CA). Cancer stem cells were limited to less than 12 passages.

Cell lines were routinely grown as monolayer cell cultures in $5 \% \mathrm{CO}_{2}$ in air, and $100 \%$ relative humidity at $37^{\circ} \mathrm{C}$. $\mathrm{HT} 29$ and $\mathrm{KM} 20$ cell lines were grown in McCoy's 5A medium (Sigma-Aldrich, St. Louis, MO) and supplemented with 10\% FBS and $1 \mathrm{X}$ antibiotic-antimycotic (Life Technologies, Carlsbad, CA). Stem cell lines were grown in Cancer Stem Cell Complete Growth Media with Serum without antibiotic on pre-coated flasks with Human Colon Cancer Stem Cell Extra-cellular Matrix (both from Celprogen). Cell passages were carried out by detaching adherent cells in a logarithmic growth phase by addition of a mixture of $0.25 \%$ trypsin with $0.02 \%$ EDTA (Sigma Aldrich) and incubating for $10-15 \mathrm{~min}$ at $37^{\circ} \mathrm{C}$. The number of viable cells was estimated with a cell counter V-CELL XR (Beckman Coulter, Miami, FL). Metformin $\mathrm{HCl}$ was purchased from Seleckchem (Pittsburgh, PA).

Cytotoxicity SRB assay. For each experiment, cell lines were seeded in two 96-well plates in normal medium $\left(5 \times 10^{3}\right.$ cells/well, $\left.100 \mu \mathrm{L}\right)$. At $24 \mathrm{~h}, 100 \mu \mathrm{L}$ of media with drugs at different concentrations were added to each well. DMSO was used as a treatment control. Cell viability was measured using the Cytoscan-SRB Cell Cytotoxicity Assay (G-Biosciences, St. Louis, MO) according to manufacturer's instructions. Cell viability was plotted as a percentage relative to DMSO treatment alone. $\mathrm{IC}_{50}$ values were approximated by plotting viability over a range of concentrations.

Western blot analysis and antibodies. Total protein lysates were resolved on a 4-12\% bis-tris gel and transferred to Immobilon PVDF transfer membranes. Membranes were incubated for $1 \mathrm{~h}$ at room temperature in blocking solution (TRIS-buffered saline containing $10 \%$ nonfat dried milk and $0.1 \%$ Tween 20 ), followed by an overnight incubation in primary antibodies at 
$4^{\circ} \mathrm{C}$. Membranes were washed 3 times and incubated with horseradish peroxidase-conjugated secondary antibodies for $1 \mathrm{~h}$. After 3 additional washes, the immune complexes on the membranes were visualized using Immobilon Western Chemiluminescent HRP substrate (EMD Millipore, Billerica, MA) or Amersham ECL (GE Life Sciences, Pittsburg, PA).

Antibodies for western blot analysis included the following: PARP (\#9542, 1:1000), Phospho-AMPKa (\#2531, Thr172, 1:1000), Phospho-S6 Ribosomal Protein (Ser235/236) (Cell Signaling, Danvers, MA); Cyclin D1 (Abcam, Cambridge, MA; \#AB34175, 1:5000); $\beta$-actin (Sigma Aldrich, \#A5441, 1:20000); anti-rabbit and anti-mouse (Santa Cruz Biotechnology, \#SC2054, \#SC-2055, 1:3000).

Patient tumor engraftment into SCID mice and PDX cell line establishment. The original patient $\mathrm{CRC}$ tumor (F0 generation) was divided and implanted into the flanks of NOD scid gamma mice (The Jackson Laboratory; 005557). When the resulting tumors (F1 generation) grew to $1 \mathrm{~cm}^{3}$, they were resected, divided into $2-\mathrm{mm}^{3}$ pieces, and implanted into 5 mice (F2 generation). All animal studies were performed in accordance with policies of the Institutional Animal Care and Use Committee and were approved by the Institutional Review Board of the University of Kentucky.

Liberase DH Research Grade (05401054001; Roche Applied Science) was resuspended in sterile water at a $2.5 \mathrm{mg} / \mathrm{ml}$ concentration and stored in single-use $100 \mu 1$ aliquots at $-80^{\circ} \mathrm{C}$. Collagenase/Hyaluronidase (07912; StemCell Technologies) was aliquoted into single-use 250 $\mu 1$ aliquots and stored at $-80^{\circ} \mathrm{C}$. Upon collection, PDX tumors (F2 generation) were placed into DMEM complete cell culture media supplemented with 1X Gibco Antibiotic-Antimycotic (15240-062; Life Technologies) for transportation. Tumor fragments were minced into 2-mm cubes using scissors and digested in $50 \mu \mathrm{g} / \mathrm{ml}$ Liberase DH (100 $\mu \mathrm{l})$ and $0.5 \mathrm{X}$ 
Collagenase/Hyaluronidase $(250 \mu \mathrm{l})$, diluted in $5 \mathrm{~mL}$ of DMEM serum free media for $4 \mathrm{~h}$ at $37^{\circ} \mathrm{C}$ with gentle agitation by magnetic stirring bar. No undigested tissue was observed; cells were washed twice with complete cell culture media and transferred into 10\% FBS DMEM media supplemented with 1X Gibco Antibiotic-Antimycotic.

Statistical analysis. Analysis of variance was employed for comparison of cell viability across DMSO and varying dose levels of FND treatment, and adjusted p-values using the Holm's procedure were calculated for pairwise comparison of each dose level with DMSO.

\section{RESULTS}

Treatment with FNDs induces cell cycle inhibition and apoptosis in metastatic CRC cells. We performed a high-throughput screen of N,N'-diarylureas to identify potent AMPK activators and selected eight active agents (Table 1)(12). Next, HT29 cells were treated with the 8 agents (FND 4a, 4b, 4c, 4d, 4e, 4f, 4g, 4h) for 48h. Decreased cell viability was evident at a drug dose as low as $5 \mu \mathrm{M}$, and was below $50 \%$ for all 8 compounds treated at the $25 \mu \mathrm{M}$ dose (Table 2). To determine whether the prominent decrease in cell viability was due to cell cycle inhibition or apoptosis induction, KM20 and HT29 CRC cells were treated with each of the 8 FNDs for $24 \mathrm{~h}$ at $25 \mu \mathrm{M}$ or $50 \mu \mathrm{M}$. Cyclin D1 expression and PARP cleavage were analyzed by western blot. Cyclin D1 expression was drastically decreased in both cell lines after treatment with FND 4b, 4c, 4d, 4e, 4f, 4g, and 4h at $25 \mu \mathrm{M}$ (Fig. 1A). Prominent PARP cleavage was observed after treatment at the $50 \mu \mathrm{M}$ dose, notably after treatment with the $4 \mathrm{~b}$ compound (Fig. 1B).

Treatment with FNDs induces cell cycle inhibition and apoptosis in cancer stem cells. CRC stem cell lines were treated with FND $4 \mathrm{~b}, 4 \mathrm{~d}, 4 \mathrm{f}, 4 \mathrm{~g}$ and $4 \mathrm{~h}$ at $50 \mu \mathrm{M}$ for $24 \mathrm{~h}$ and analyzed for cyclin D1 expression and PARP cleavage. Cyclin D1 expression was decreased in all 
treatment groups; prominent PARP cleavage was observed in both stem cell lines only after treatment with FND 4b (Fig. 2A). Activation of apoptosis is especially important for elimination of cancer stem cells, since these cells are progenitors for tumor progression; FND $4 \mathrm{~b}$ treatment induced apoptosis in both metastatic cancer cells and cancer stem cells. To confirm that AMPK activation was dose responsive in CRC stem cells, we treated CRC stem cell line 1 with 5, 25 and $50 \mu \mathrm{M}$ of FND 4b. Our results showed a dose-dependent AMPK activation after FND 4b treatment (Fig. 2B).

Next, we used compound $4 \mathrm{~b}$ to evaluate dose-dependent AMPK activation in KM20 and HT29 cells. We observed AMPK activation starting with as little as $10 \mu \mathrm{M}$ (Fig. 3A). We also examined the dose dependent effects of FND 4b treatment on cell viability (Fig. 3B), cell cycle, and apoptosis induction in KM20 and HT29 cells. KM20 cells were more sensitive to compound $4 \mathrm{~b}$ treatment and showed marked suppression of cyclin D1 expression at a dose of $10 \mu \mathrm{M}$. PARP cleavage was detected in both cell lines starting at a $40 \mu \mathrm{M}$ dose.

\section{Treatment with FND $4 b$ induces cell cycle inhibition and apoptosis in pik3ca mutant}

colorectal cancer cells. We evaluated whether the pik3ca mutation protects cancer cells against FND 4b treatment. HCT116 pik3ca mutant and wild-type CRC cell lines were treated with FND $4 \mathrm{~b}$ at $10,20,30,40$ and $50 \mu \mathrm{M}$ for $24 \mathrm{~h}$. Both cell lines showed strong cell cycle inhibition but required higher dosages compared to KM20 and HT29 cell lines. PARP cleavage was noted with FND $4 \mathrm{~b}$ treatment at $20 \mu \mathrm{M}$ (Fig. 4A). These results show that the HCT116 pik3ca mutant and wild-type cells have a similar pattern of cell cycle inhibition and apoptosis in response to FND $4 \mathrm{~b}$ treatment.

Metformin, which is a known activator of AMPK and is used for diabetes treatment and cancer prevention, activates AMPK at millimolar levels (15). AMPK downregulates TOR/S6K 
activity via TSC2 in response to stress (16). We treated HT29 and KM20 cells with FND 4b at $10,20,30 \mu \mathrm{M}$ and with metformin at 5, 10 and $20 \mathrm{mM}$ for $24 \mathrm{~h}$ to compare the effect on cyclin D1 expression and S6 phosphorylation at Ser234/235. Both metformin and FND 4b decreased phosphorylation of the S6 protein, a downstream effector of mTOR that is a crucial signaling pathway for proliferation and survival of cancer cells in vitro as well as tumors in vivo (Fig. 4B, C). Our results demonstrated that FND $4 \mathrm{~b}$ had a similar effect on cell cycle inhibition and inhibition of S6 phosphorylation at the $20 \mu \mathrm{M}$ dose as compared to the $10 \mathrm{mM}$ dose of metformin.

Treatment of CRC cells, stem cells and PDX cell line with low dose FND $4 b$. To determine the effect of FND treatment on AMPK $\alpha$ activation, HT29 cells were treated with low dosages (i.e., 5 and $10 \mu \mathrm{M}$ ) of FND $4 \mathrm{~b}$ for 12, 24, 48 and 72h. FND treatment demonstrated a long-lasting effect on AMPK activation at $10 \mu \mathrm{M}$ (Fig. 5A). Low-dose FND $4 \mathrm{~b}$ treatment resulted in a strong AMPK $\alpha$ activation, and decreased cyclin D1 expression in CRC stem cells at 48h (Fig. 5B, C). Next, we established a cell line from a patient-derived xenograft (PDX) and treated it with low-dose FND $4 \mathrm{~b}$ for $48 \mathrm{~h}$. Cyclin D1 expression was markedly suppressed in the PDX cell line (Fig. 5D). FND treatment at 5, 7.5 and $10 \mu \mathrm{M}$ significantly decreased stem cells and PDXL proliferation (Fig. 5 B, C, D; lower panels). Low-dose FND treatment did not increase PARP cleavage in all tested cells (data not shown). These results demonstrate a longlasting effect of low-dose FND $4 \mathrm{~b}$ treatment on AMPK $\alpha$ activation and cell cycle inhibition.

\section{DISCUSSION}

The central regulatory role played by AMPK in energy homeostasis makes it an attractive target for treatment of various diseases such as diabetes and cancer $(6,7,17)$. Recent efforts have focused on elucidating the complex role of AMPK in cancer cell viability (18). We examined the 
effects of 8 fluorinated N,N'-diarylureas as AMPK activators on CRC metastatic and stem cell lines to evaluate their potential utility as chemotherapeutic agents for CRC. The FNDs that were used in this study represent a new class of AMPK activators with no effect on AKT or ERK, unlike other N,N' diarylureas [12]. We confirmed that FND treatment of CRC metastatic and stem cell lines resulted in dose-dependent AMPK activation. High doses of traditional AMPK activators, such as AICAR and metformin, were required to achieve anti-cancer effects (10-12, 19). However, similar to FNDs, more recent AMPK activators showed anti-tumorigenic effects at lower concentrations. Chen et al. (19) showed that plumbagin, an AMPK activator, induced apoptosis and inhibited growth of CRC cell lines at a treatment concentration of $10 \mu \mathrm{M}$. Kaushik et al. (20) showed that honokiol, another AMPK activating compound, inhibited melanoma growth and spheroid-forming capacity (i.e., stemness) through AMPK activation at concentrations up to $50 \mu \mathrm{M}$. Finally, Valtorta et al. (21) showed that 1-4 diaryl-azetidinone, also a novel AMPK activator, inhibited human CRC xenografts in mouse models at $\mathrm{IC}_{50}$ in the $\mathrm{nM}$ to $1 \mu \mathrm{M}$ range. Taken together, these studies suggested that targeting cancer cells with novel AMPK activators represent an effective strategy for the treatment of different types of cancers. Thus, the beneficial effects on metastatic cancer cells by AMPK activation provide a rationale for further studies, to determine the potential clinical utility of AMPK activators, like FNDs, on cancer stem cells.

In our study, we evaluated the effect of FNDs on CRC stem cells. Many cancer stem cell models have been described, but a unifying theme in tumorigenesis is that tumors are not homogeneous. A hierarchical structure within tumors includes a small subset of cells with longterm self-renewal and differentiation capacity (3). CRC, in particular, is known to possess cancer stem cells (22). In order to survive, re-populate, and differentiate, cancer stem cells have 
developed several mechanisms that provide resistance to the effects of anti-neoplastic agents. These mechanisms include resistance to DNA damage, drug penetration, apoptosis, and reactive oxygen species (ROS) (3-5). Up-regulation of the DNA repair machinery and down-regulation of telomerase allow cancer stem cells to maintain their genetic integrity. Cancer stem cells also upregulate efflux transporters from the ATP-binding cassette (ABC) gene family to efficiently extrude chemotherapy agents. Resistance to apoptosis occurs, in part, through Akt pathway activation and increased production of apoptosis inhibitor proteins. Finally, cancer stem cells increase their free radical scavenging machinery to protect themselves from ROS damage (4). Several studies have investigated the role of stem cells in treatment resistance $(2,11)$. For example, Zhou et al. [2] created cisplatin-resistant CRC cells and found that these cells had stem cell-like markers. Treatment with salinomycin caused an accumulation of ROS and downregulation of anti-apoptotic molecules, which suggested that salinomycin was able to overcome the cisplatin resistance of CRC cells. Since cancer stem cells possess these survival mechanisms, cancer treatment plans should include therapy to specifically target cancer stem cells in order to reduce future recurrence and metastasis.

While the specific role of AMPK in cancer stem cells compared with the non-stem cell population has not yet been fully characterized, several studies have shown that metformin, an AMPK activator, is preferentially cytotoxic to cancer stem cells in pancreatic and breast cancers $(10,11,23)$. Similarly, in our present study, we showed that FND treatment resulted in cell cycle arrest in CRC stem cells. AMPK activation led to inhibition of macromolecular synthesis, inhibition of mTORC1, and onset of the 'anti-Warburg effect' $(7,24,25)$, all of which led to the inhibition of cancer cell proliferation. Hardie and Alessi (7) described several AMPK tumor suppressor functions that included cell cycle arrest through stabilization of p53, p21 and p27. 
Particularly in cancer stem cells, it is likely that the anti-Warburg effect targets the utilization of anaerobic glycolysis by cancer stem cells, and decreases their ability to use AKT-mTOR. AMPK activation of apoptosis resulted from p53 phosphorylation; phosphorylated AMPK subsequently accumulated in the mitochondria and interacted with Bak to induce apoptosis (8). Our results demonstrated that AMPK activation reduced the ability of cancer stem cells to hijack energy metabolism for growth and proliferation and triggered an apoptotic cascade. In summary, we demonstrated that FNDs activated AMPK at micromolar concentrations, which resulted in consistent cell cycle arrest and apoptosis in all cancer cell lines that were studied. These findings provide additional information regarding the role of AMPK activation in cancer stem cells and demonstrate a potential role of FNDs in the treatment of metastatic CRC.

\section{ACKNOWLEDGEMENTS}

The authors thank the Markey Cancer Center's Research Communications Office for help with manuscript preparation, and the Biostatistics and Bioinformatics Shared Resource Facility for statistical analysis. The contents of this manuscript are solely the responsibility of the authors and do not necessarily represent the official views of the grant funding agencies. 


\section{REFERENCES}

1. Siegel R, Ma J, Zou Z, Jemal A. Cancer statistics, 2014. CA Cancer J Clin 2014;64:9-29.

2. Zhou J, Li P, Xue X, He S, Kuang Y, Zhao H, et al. Salinomycin induces apoptosis in cisplatin-resistant colorectal cancer cells by accumulation of reactive oxygen species. Toxicol Lett 2013;222:139-45.

3. Beck B, Blanpain C. Unravelling cancer stem cell potential. Nat Rev Cancer 2013; $13: 727-38$.

4. Morrison R, Schleicher SM, Sun Y, Niermann KJ, Kim S, Spratt DE, et al. Targeting the mechanisms of resistance to chemotherapy and radiotherapy with the cancer stem cell hypothesis. J Oncol 2011;2011:941876.

5. Ito K, Suda T. Metabolic requirements for the maintenance of self-renewing stem cells. Nat Rev Mol Cell Biol 2014;15:243-56.

6. Mihaylova MM, Shaw RJ. The AMPK signalling pathway coordinates cell growth, autophagy and metabolism. Nat Cell Biol 2011;13:1016-23.

7. Hardie DG, Alessi DR. LKB1 and AMPK and the cancer-metabolism link - ten years after. BMC Biol 2013;11:36.

8. Nieminen AI, Eskelinen VM, Haikala HM, Tervonen TA, Yan Y, Partanen JI, et al. Mycinduced AMPK-phospho p53 pathway activates Bak to sensitize mitochondrial apoptosis. Proc Natl Acad Sci U S A 2013;110:E1839-48.

9. Sehdev A, Shih YC, Vekhter B, Bissonnette MB, Olopade OI, Polite BN. Metformin for primary colorectal cancer prevention in patients with diabetes: a case-control study in a US population. Cancer 2015;121:1071-8. 
10. Hirsch HA, Iliopoulos D, Tsichlis PN, Struhl K. Metformin selectively targets cancer stem cells, and acts together with chemotherapy to block tumor growth and prolong remission. Cancer Res 2009;69:7507-11.

11. Song CW, Lee H, Dings RP, Williams B, Powers J, Santos TD, et al. Metformin kills and radiosensitizes cancer cells and preferentially kills cancer stem cells. Sci Rep 2012;2:362.

12. Sviripa V, Zhang W, Conroy MD, Schmidt ES, Liu AX, Truong J, et al. Fluorinated N,N'-diarylureas as AMPK activators. Bioorg Med Chem Lett 2013;23:1600-3.

13. Gulhati P, Bowen KA, Liu J, Stevens PD, Rychahou PG, Chen M, et al. mTORC1 and mTORC2 regulate EMT, motility, and metastasis of colorectal cancer via RhoA and Rac1 signaling pathways. Cancer Res 2011;71:3246-56.

14. Guo XN, Rajput A, Rose R, Hauser J, Beko A, Kuropatwinski K, et al. Mutant PIK3CAbearing colon cancer cells display increased metastasis in an orthotopic model. Cancer Res 2007;67:5851-8.

15. Zhou G, Myers R, Li Y, Chen Y, Shen X, Fenyk-Melody J, et al. Role of AMP-activated protein kinase in mechanism of metformin action. J Clin Invest 2001;108:1167-74.

16. Inoki K, Zhu T, Guan KL. TSC2 mediates cellular energy response to control cell growth and survival. Cell 2003; $115: 577-90$.

17. Fay JR, Steele V, Crowell JA. Energy homeostasis and cancer prevention: the AMPactivated protein kinase. Cancer Prev Res (Phila) 2009;2:301-9.

18. Liang J, Mills GB. AMPK: a contextual oncogene or tumor suppressor? Cancer Res 2013;73:2929-35. 
19. Chen MB, Zhang Y, Wei MX, Shen W, Wu XY, Yao C, et al. Activation of AMPactivated protein kinase (AMPK) mediates plumbagin-induced apoptosis and growth inhibition in cultured human colon cancer cells. Cell Signal 2013;25:1993-2002.

20. Kaushik G, Kwatra D, Subramaniam D, Jensen RA, Anant S, Mammen JM. Honokiol affects melanoma cell growth by targeting the AMP-activated protein kinase signaling pathway. Am J Surg 2014;208:995-1002; discussion 1-2.

21. Valtorta S, Nicolini G, Tripodi F, Meregalli C, Cavaletti G, Avezza F, et al. A novel AMPK activator reduces glucose uptake and inhibits tumor progression in a mouse xenograft model of colorectal cancer. Invest New Drugs 2014;32:1123-33.

22. Fanali C, Lucchetti D, Farina M, Corbi M, Cufino V, Cittadini A, et al. Cancer stem cells in colorectal cancer from pathogenesis to therapy: controversies and perspectives. World J Gastroenterol 2014;20:923-42.

23. Fasih A, Elbaz HA, Huttemann M, Konski AA, Zielske SP. Radiosensitization of pancreatic cancer cells by metformin through the AMPK pathway. Radiat Res 2014;182:50-9.

24. Faubert B, Boily G, Izreig S, Griss T, Samborska B, Dong Z, et al. AMPK is a negative regulator of the Warburg effect and suppresses tumor growth in vivo. Cell Metab 2013; $17: 113-24$.

25. Shackelford DB, Shaw RJ. The LKB1-AMPK pathway: metabolism and growth control in tumour suppression. Nat Rev Cancer 2009;9:563-75. 
Table 1. Fluorinated $N, N$ '-diarylureas (FNDs) with substituents $\mathrm{X}$ or $\mathrm{Y}$ in the "first" aryl ring and substituents A,B,C,D in the "second aryl" ring. AMPK activation ratios were relative to compound 3 from a previous study [13].

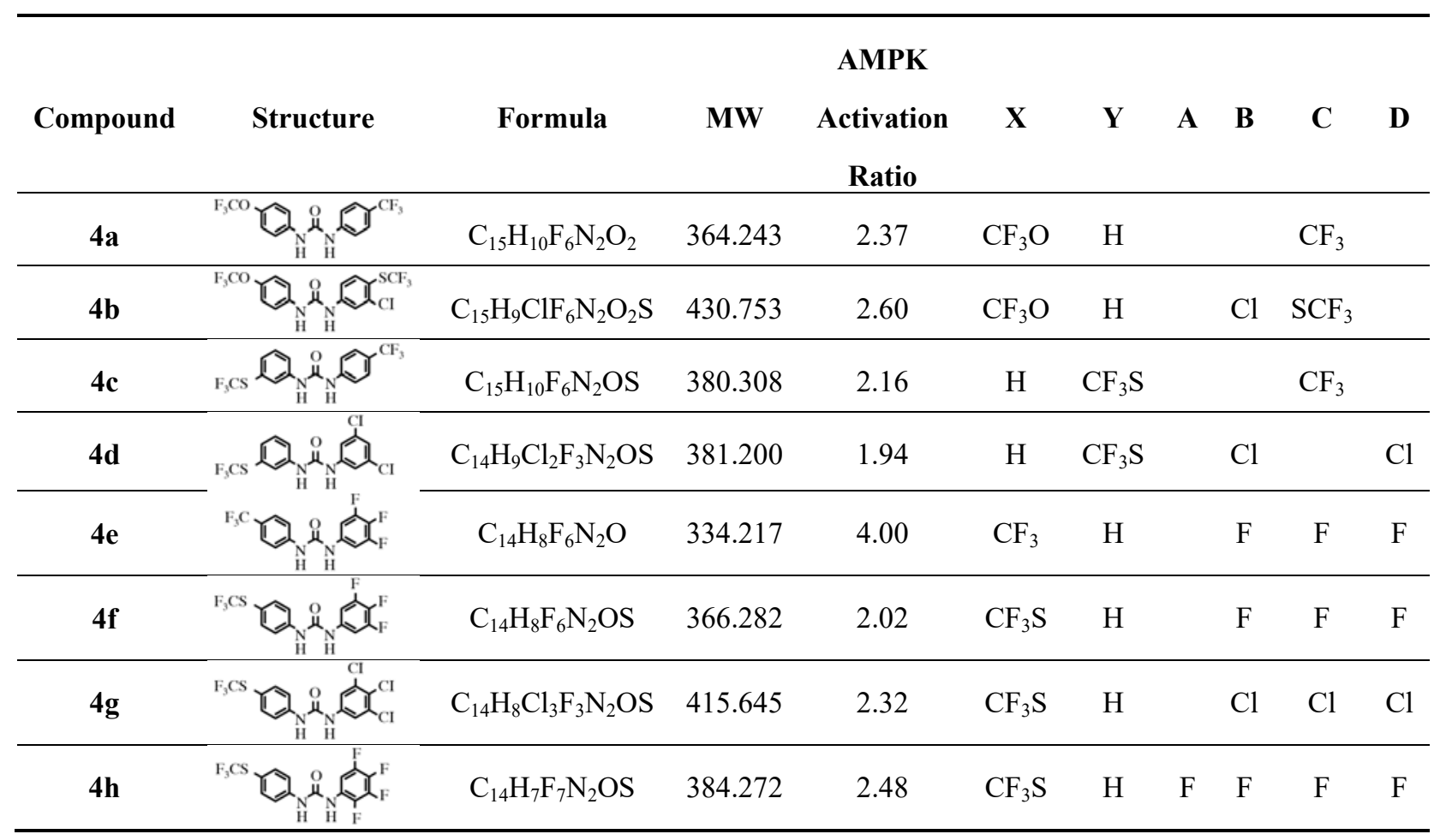


Table 2. Effect of FNDs on metastatic CRC cell viability. HT29 cells were seeded in 96-well plates in complete medium $\left(5 \times 10^{3} /\right.$ well) and treated with 8 different FNDs (4a-4h). DMSO (25 $\mu \mathrm{M}$ ) was used as a treatment control. Cell viability was measured using an SRB assay after $48 \mathrm{~h}$ of FND exposure and plotted as a percentage relative to DMSO treatment alone. Each measurement was performed in sextuplicate; ${ }^{*} \mathrm{p} \leq 0.05$.

\begin{tabular}{ccccc}
\hline Compound & Control & $\mathbf{5} \boldsymbol{\mu \mathbf { M }}$ & $\mathbf{1 0} \boldsymbol{\mu M}$ & $\mathbf{2 5} \boldsymbol{\mu M}$ \\
\hline $\mathbf{4 a}$ & 100 & $67.7^{*}$ & $23.1^{*}$ & $15.5^{*}$ \\
$\mathbf{4 b}$ & 100 & $36.0^{*}$ & $22.2^{*}$ & $8.3^{*}$ \\
$\mathbf{4 c}$ & 100 & $21.4^{*}$ & $21.0^{*}$ & $6.6^{*}$ \\
$\mathbf{4 d}$ & 100 & $24.1^{*}$ & $19.3^{*}$ & $4.8^{*}$ \\
$\mathbf{4 e}$ & 100 & $29.9^{*}$ & $23.6^{*}$ & $9.7^{*}$ \\
$\mathbf{4 f}$ & 100 & $20.9^{*}$ & $21.0^{*}$ & $5.1^{*}$ \\
$\mathbf{4 g}$ & 100 & $22.6^{*}$ & $23.2^{*}$ & $7.5^{*}$ \\
$\mathbf{4 h}$ & 100 & $23.2^{*}$ & $20.0^{*}$ & $6.3^{*}$ \\
\hline
\end{tabular}




\section{Figure Legends}

Figure 1. Effect of FNDs on cyclin D1 expression and PARP cleavage in metastatic CRC cell lines. A, B. KM20 and HT29 CRC cells were seeded in 6-well plates $\left(8 \times 10^{5} /\right.$ well) in complete medium and treated 24h later with 8 different FNDs (4a-4h) for $24 \mathrm{~h}$ at $25 \mu \mathrm{M}(\mathbf{A})$ and $50 \mu \mathrm{M}(\mathbf{B})$. Cyclin D1 expression and PARP cleavage (PARP cleaved product $85 \mathrm{kDa}$; arrow) was assessed by western blot analysis; $\beta$-actin was used as a loading control.

Figure 2. Effect of FNDs on PARP cleavage and cyclin D1 and pAMPK expression in CRC stem cell lines. A. CRC stem cell line 1 and stem cell line 2 were seeded in 6-well plates in complete medium and treated $24 \mathrm{~h}$ later with FNDs $4 \mathrm{~b}, 4 \mathrm{~d}, 4 \mathrm{f}, 4 \mathrm{~g}$ and $4 \mathrm{~h}$ at $50 \mu \mathrm{M}$ for $24 \mathrm{~h}$. Cyclin D1 expression and PARP cleavage (PARP cleaved product $85 \mathrm{kDa}$; arrow) was analyzed by western blot. DMSO $(50 \mu \mathrm{M})$ was used as a treatment control, and $\beta$-actin was used as a loading control. B. CRC stem cell line 1 was seeded in 6 -well plates $\left(8 \times 10^{5} /\right.$ well $)$ in complete medium and treated $24 \mathrm{~h}$ later with FND $4 \mathrm{~b}$ at 5, 25 and $50 \mu \mathrm{M}$ for $12 \mathrm{~h}$. AMPK $\alpha$ phosphorylation (Thr172) was analyzed by western blot. DMSO $(50 \mu \mathrm{M})$ was used as a treatment control, and $\beta$ actin was used as a loading control. Densitometry was performed with ImageJ software; relative pAMPK $\alpha$ (Thr172) band intensity was normalized to $\beta$-actin and quantified with respect to control set at 1.0.

Figure 3. Treatment of CRC cell lines with FND 4b. A. KM20 and HT29 CRC cells were seeded in 6-well plates $\left(8 \times 10^{5} /\right.$ well) in complete medium and treated $24 \mathrm{~h}$ later with FND $4 \mathrm{~b}$ at 10, 20, 30, 40 and $50 \mu \mathrm{M}$ for $12 \mathrm{~h}$. AMPK $\alpha$ phosphorylation (Thr172) was assessed by western blot analysis. DMSO $(50 \mu \mathrm{M})$ was used as a treatment control, and $\beta$-actin was used as a loading 
control. Densitometry was performed with ImageJ software; relative pAMPK $\alpha$ (Thr172) band intensity was normalized to $\beta$-actin and quantified with respect to control set at 1.0. B. KM20 and HT29 CRC cells were seeded in 6-well plates (8x10 $/$ well) in complete medium for $24 \mathrm{~h}$ and treated with FND $4 \mathrm{~b}$ at 10, 20, 30, 40 and $50 \mu \mathrm{M}$ for 24h. Cyclin D1 expression and PARP cleavage (cleaved product $85 \mathrm{kDa}$; arrow) was assessed by western blot analysis. DMSO (50 $\mu \mathrm{M})$ was used as a treatment control, and $\beta$-actin was used as a loading control.

Figure 4. Treatment of Pik3ca mutant CRC cells with FND 4b. A. HCT116 pik3ca wild-type and pik3ca mutant cell lines were seeded in 6-well plates $\left(8 \times 10^{5} /\right.$ well $)$ in complete medium for $24 \mathrm{~h}$ and treated with FND $4 \mathrm{~b}$ at 10, 20, 30, 40 and $50 \mu \mathrm{M}$ for $24 \mathrm{~h}$. Cyclin D1 expression and PARP cleavage (PARP cleaved product $85 \mathrm{kDa}$; arrow) was analyzed by western blot. DMSO $(50 \mu \mathrm{M})$ was used as a treatment control; $\beta$-actin was used as a loading control. B. C. HT29 and KM20, respectively, cells were seeded in 24 -well plates $\left(5 \times 10^{5} /\right.$ well) in complete medium and treated $24 \mathrm{~h}$ later with 5, 10, $20 \mathrm{mM}$ metformin and FND $4 \mathrm{~b}$ at 10, 20, $30 \mu \mathrm{M}$ for 24h. Cyclin D1 (arrow), S6 phosphorylation (Ser234/235) and total S6 expression was analyzed by western blot. DMSO $(30 \mu \mathrm{M})$ was used as a treatment control; $\beta$-actin was used as a loading control.

Figure 5. Low dose FND 4b treatment. A. HT29 CRC cells were seeded in 6-well plates $\left(8 \times 10^{5} /\right.$ well $)$ in complete medium for $24 \mathrm{~h}$ and treated with FND $4 \mathrm{~b}$ at 5 and $10 \mu \mathrm{M}$ for $12,24,48$ and 72h. AMPK $\alpha$ phosphorylation (Thr172) was analyzed by western blot. DMSO (10 $\mu \mathrm{M})$ was used as a treatment control; $\beta$-actin was used as a loading control. B, C. (Upper panels) CRC stem cell line 1 and stem cell line 2 were seeded in 6-well plates in complete medium and treated 24h later with $5 \mu \mathrm{M}$ FND 4b for 48h. AMPK $\alpha$ phosphorylation (Thr172) and cyclin D1 expression were analyzed by western blot. DMSO $(10 \mu \mathrm{M})$ was used as a treatment control; $\beta$ - 
actin was used as a loading control. (Lower panels) Stem cells were seeded in 96-well plates in complete medium ( $5 \times 10^{3} /$ well) and treated with FND 4b. Cell viability (lower panels) was measured using an SRB assay after 48h of FND exposure and plotted as a percentage relative to DMSO treatment alone. Graphic representations are the mean $\pm \mathrm{SE}$; each measurement was performed in sextuplicate. D. PDX cell line was seeded in 6 -well plates $\left(8 \times 10^{5} /\right.$ well $)$ in complete medium and treated 24h later with FND $4 \mathrm{~b}$ at 5 and $10 \mu \mathrm{M}$ for $48 \mathrm{~h}$. Cyclin D1 expression was analyzed by western blot (upper panel). DMSO $(10 \mu \mathrm{M})$ was used as a treatment control; $\beta$-actin was used as a loading control. PDX cell line was seeded in 96-well plates in complete medium $\left(5 \times 10^{3} /\right.$ well) and treated with FND 4 b. Cell viability (lower panel) was measured using an SRB assay after $48 \mathrm{~h}$ of FND exposure and plotted as a percentage relative to DMSO treatment alone. Graphic representations are the mean $\pm \mathrm{SE}$; each measurement was performed in sextuplicate; $* \mathrm{p} \leq 0.05$. 
A

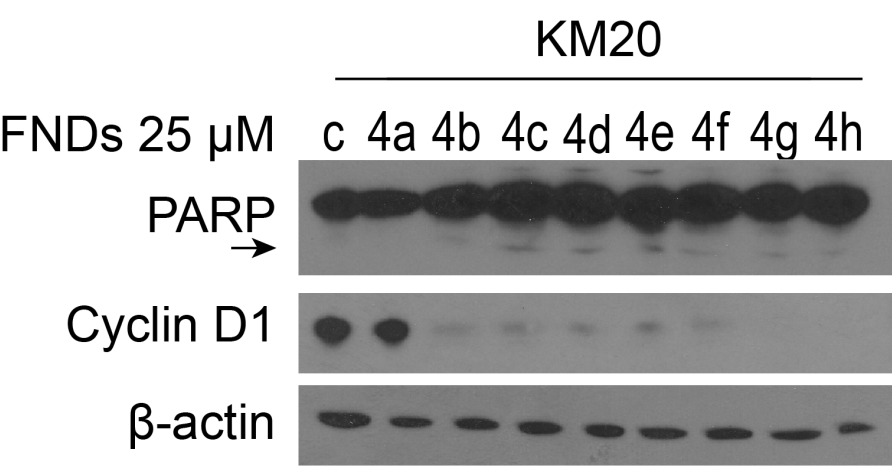

B

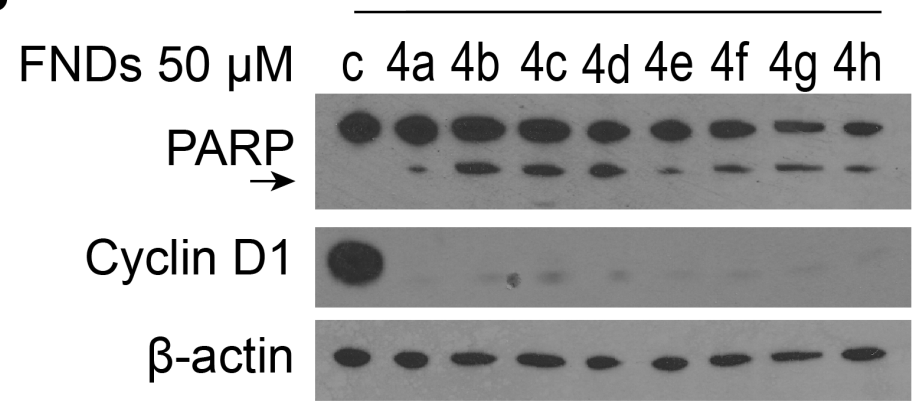

HT29
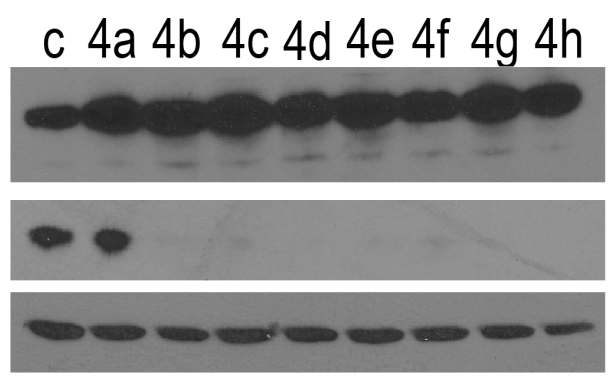

HT29

c $4 \mathrm{a} 4 \mathrm{~b} 4 \mathrm{c} 4 \mathrm{~d} 4 \mathrm{e} 4 \mathrm{f} 4 \mathrm{~g} 4 \mathrm{~h}$
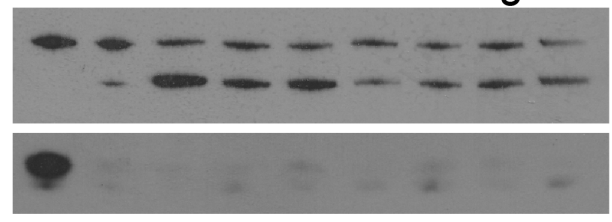

$00+\infty-\infty+\infty$

Figure 1 
A

CRC stem 1

$50 \mu \mathrm{M} \quad \mathrm{c} 4 \mathrm{~b} 4 \mathrm{~d} 4 \mathrm{f} 4 \mathrm{~g} 4 \mathrm{~h}$

PARP $\rightarrow$

Cyclin D1

$\beta$-actin
CRC stem 2
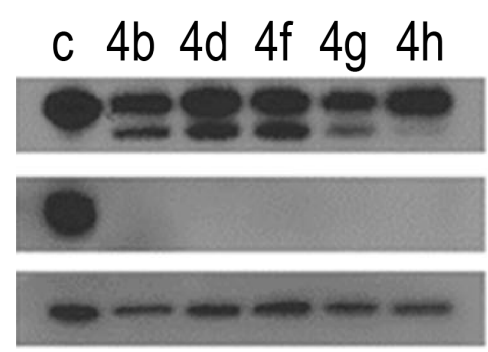

B

CRC stem 1

FND $4 b \mu \mathrm{M} \quad$ c $\quad 5 \quad 25 \quad 50$ pAMPKa (Thr172)

\section{$\beta$-actin}

(1)

Densitometry

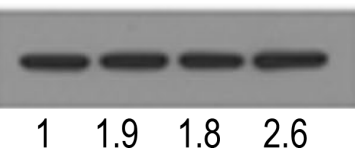

Figure 2 


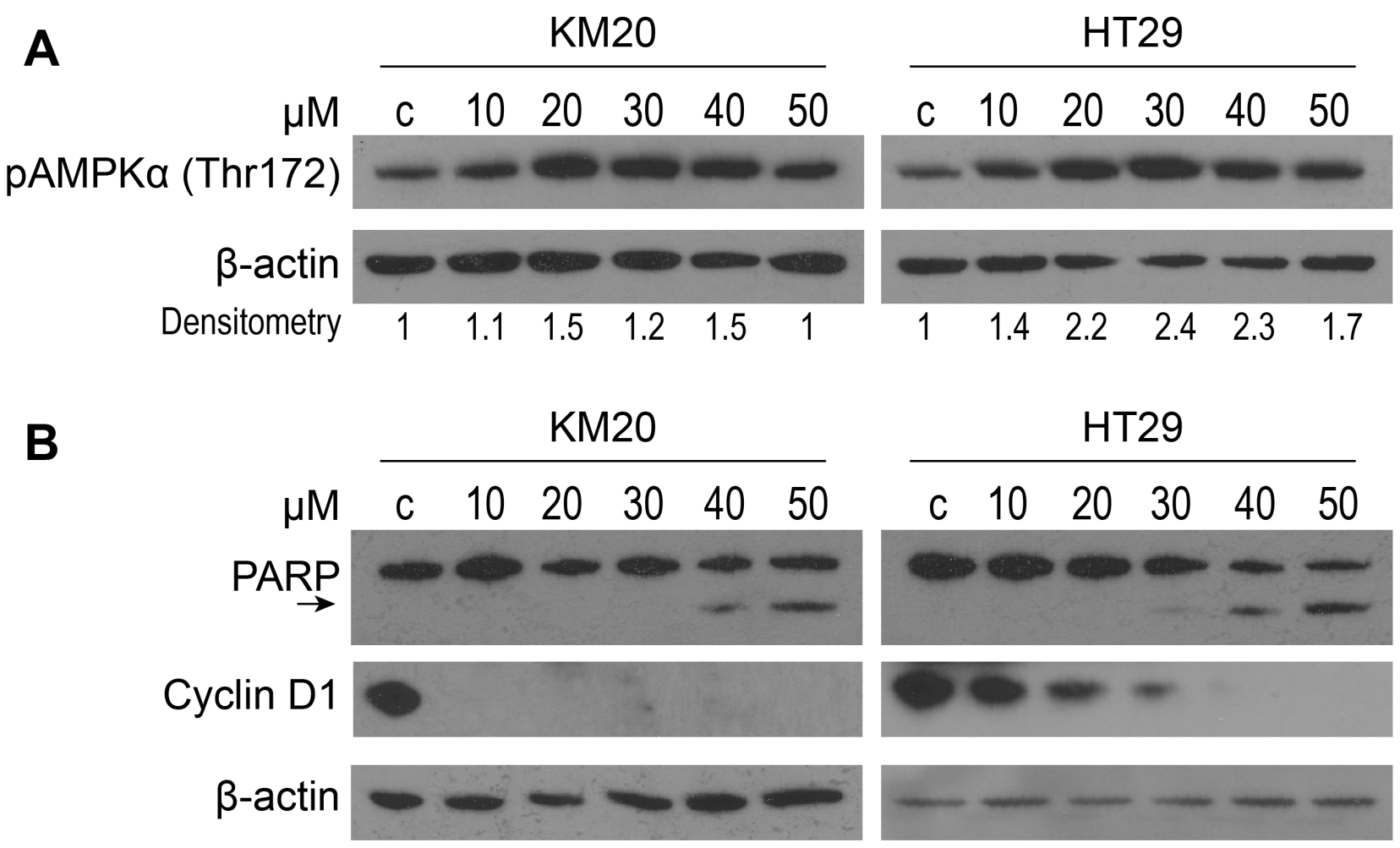

Figure 3 


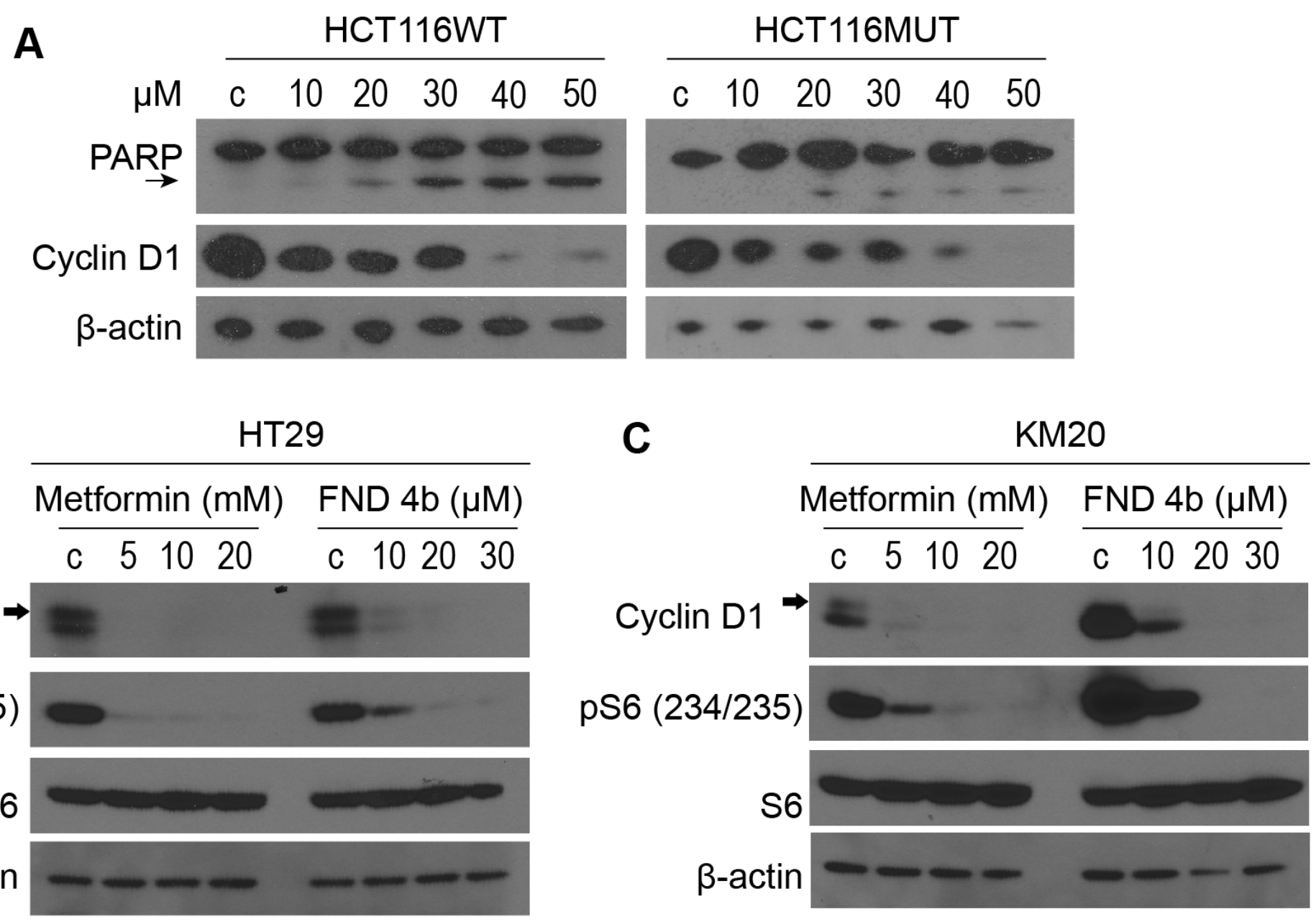

Figure 4 


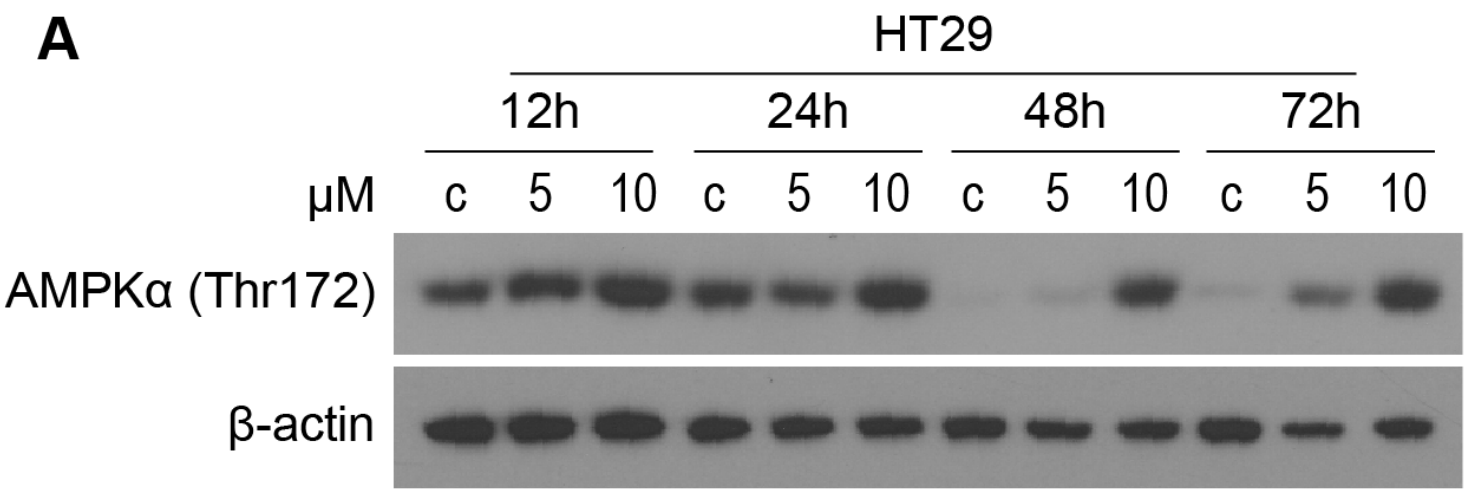

B

Stem 1 $\mu \mathrm{M} \quad \mathrm{C} \quad 5$

AMPKa (Thr172)

Cyclin D1

$\beta$-actin

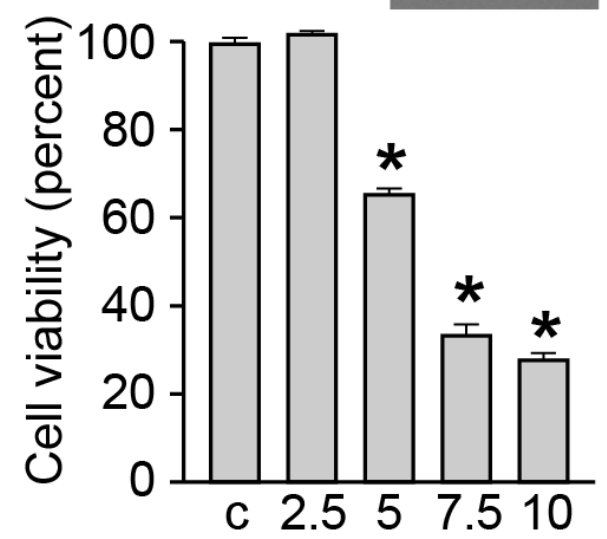

Stem cell line $1(\mu \mathrm{M})$
C

Stem 2

$\mu \mathrm{M} \quad \mathrm{C} \quad 5$

AMPKa (Thr172)

Cyclin D1

$\beta$-actin

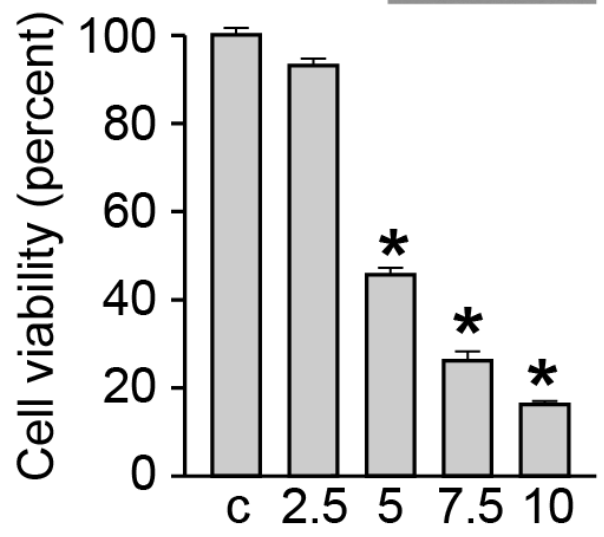

Stem cell line $2(\mu \mathrm{M})$
D

PDX

$\mu \mathrm{M} \mathrm{C} \quad 5 \quad 10$

AMPKa (Thr172)

Cyclin D1

$\beta$-actin

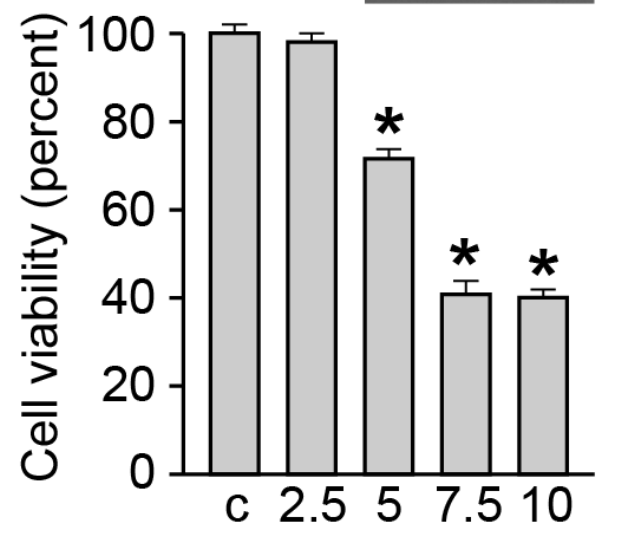

PDX cell line $(\mu M)$

Figure 5 


\section{AACR \\ Molecular Cancer Therapeutics}

\section{Fluorinated N,N'-Diarylureas As Novel Therapeutic Agents Against Cancer Stem Cells}

Dasha E Kenlan, Piotr Rychahou, Vitaliy M Sviripa, et al.

Mol Cancer Ther Published OnlineFirst March 3, 2017.

Updated version Access the most recent version of this article at: doi:10.1158/1535-7163.MCT-15-0634

Author Author manuscripts have been peer reviewed and accepted for publication but have not yet been Manuscript edited.

E-mail alerts Sign up to receive free email-alerts related to this article or journal.

Reprints and To order reprints of this article or to subscribe to the journal, contact the AACR Publications Subscriptions Department at pubs@aacr.org.

Permissions To request permission to re-use all or part of this article, use this link http://mct.aacrjournals.org/content/early/2017/03/03/1535-7163.MCT-15-0634.

Click on "Request Permissions" which will take you to the Copyright Clearance Center's (CCC) Rightslink site. 